\title{
Two cases of pneumococcal spondylitis in the same household: a case report
}

\author{
Ken Goda', Tsuneaki Kenzaka ${ }^{1,2^{*}}$ (D) Bin Chang $^{3}$ and Hozuka Akita ${ }^{1}$
}

\begin{abstract}
Background: Pneumococci normally reside in the nasopharynx, and when individuals are in close contact with each other such as in a community or a family setting, it is transmitted from carriers and sometimes results in pneumonia.

Case presentation: Case 1: The patient was a 55-year-old woman who visited the hospital complaining of fever and headache. Lumbar pain occurred on hospital day 2, and purulent spondylitis was diagnosed using lumbar MRI. Blood culture results were positive for pneumococcus.

Case 2: The patient was a 60-year-old male, and the husband of the woman in the Case 1. Fever and lumbar pain occurred on the same day similar to Case 1. Inpatient treatment was provided for pneumococcal bacteremia. Although no abnormalities were observed on the lumbar MRI scan taken on hospital day 2, purulent spondylitis was diagnosed by an MRI taken on hospital day 9. Both patients received appropriate antimicrobial treatment. When bacterial strain analysis was performed on samples from Cases 1 and 2, we noted that the capsule serotype was $12 \mathrm{~F}$, the drug sensitivity was similar, and the sequence typing matched completely, indicating that the causative bacteria for both cases were identical.

Conclusions: Pneumococcal bacteremia and purulent spondylitis can occur in different members of a family simultaneously. Pneumococcal infection can transmit between two close family members; hence, whenever a close family member of an individual who has already been infected with pneumococcal infection, develops fever, the possibility of transmission must be considered.
\end{abstract}

Keywords: Pneumococcal infection, Fever, Spondylitis, Bacteremia

\section{Background}

Pneumococci normally reside in the nasopharynx of an infant and can cause pneumonia, sepsis, and meningitis in susceptible individuals [1]. Pneumococcal infection is known to be transmitted in the carrier state not only in infants but also in adults in community and family settings where people live in close proximity to each other $[2,3]$. Pneumococcal pneumonia infection is reportedly transmitted among persons living in close contact with each other, such as those within a family [4] or, as a rare occurrence, among nursing home residents [1].

\footnotetext{
* Correspondence: smile.kenzaka@jichi.ac.jp

${ }^{1}$ Department of Internal Medicine, Hyogo Prefectural Kaibara Hospital, 5208-1, Kaibara, Kaibara-cho, Tanba, Hyogo 669-3395, Japan

2Division of Community Medicine and Career Development, Kobe University Graduate School of Medicine, 2-1-5, Arata-cho, Hyogo-ku, Kobe, Hyogo 652-0032, Japan

Full list of author information is available at the end of the article
}

\section{Case presentation}

Case 1

The patient was a 55-year-old woman who visited the emergency room in the morning complaining of headache and fever. She was able to perform her daily activities independently and lived with her infant grandchild. She had no medical history of pneumonia and no history of pneumococcal vaccination. She received treatment for diabetes mellitus. The rapid influenza test result was negative, but blood samples were taken for culture test after which the patient was sent home with supportive therapy. However, because the headache continued to worsen, she returned to the emergency room later that evening and was hospitalized. The results of the blood test taken at this stage are presented in Table 1. Gram-positive cocci were detected in the blood culture taken during the initial visit, and treatment was initiated with $2 \mathrm{~g}$ ceftriaxone every $24 \mathrm{~h}$ combined with $1 \mathrm{~g}$

(c) The Author(s). 2018 Open Access This article is distributed under the terms of the Creative Commons Attribution 4.0 International License (http://creativecommons.org/licenses/by/4.0/) which permits unrestricted use, distribution, and 
Table 1 Laboratory data of Case 1 on admission

\begin{tabular}{lll}
\hline Parameter & Recorded value & Standard value \\
\hline White blood cell count & $8.27 \times 10^{9} / \mathrm{L}$ & $4.50-7.50 \times 10^{9} / \mathrm{\mu L}$ \\
$\quad$ Neutrophils & $91.5 \%$ & \\
$\quad$ Lymphocytes & $6.9 \%$ & \\
Hemoglobin & $12.7 \mathrm{~g} / \mathrm{dL}$ & $11.3-15.2 \mathrm{~g} / \mathrm{dL}$ \\
Hematocrit & $33.0 \%$ & $36-45 \%$ \\
Platelets & $141 \times 10^{9} / \mathrm{L}$ & $130-350 \times 10^{9} / \mathrm{L}$ \\
C-reactive protein & $10.1 \mathrm{mg} / \mathrm{dL}$ & $\leq 0.60 \mathrm{mg} / \mathrm{dL}$ \\
Total protein & $7.0 \mathrm{~g} / \mathrm{dL}$ & $6.9-8.4 \mathrm{~g} / \mathrm{dL}$ \\
Albumin & $3.8 \mathrm{~g} / \mathrm{dL}$ & $3.9-5.1 \mathrm{~g} / \mathrm{dL}$ \\
Aspartate aminotransferase & $25 \mathrm{U} / \mathrm{L}$ & $11-30 \mathrm{U} / \mathrm{L}$ \\
Alanine aminotransferase & $20 \mathrm{U} / \mathrm{L}$ & $4-30 \mathrm{U} / \mathrm{L}$ \\
Lactate dehydrogenase & $258 \mathrm{U} / \mathrm{L}$ & $109-216 \mathrm{U} / \mathrm{L}$ \\
Creatine phosphokinase & $119 \mathrm{U} / \mathrm{L}$ & $40-150 \mathrm{U} / \mathrm{L}$ \\
Blood nitrogen urea & $12.8 \mathrm{mg} / \mathrm{dL}$ & $8-20 \mathrm{mg} / \mathrm{dL}$ \\
Creatinine & $0.70 \mathrm{mg} / \mathrm{dL}$ & $0.63-1.03 \mathrm{mg} / \mathrm{dL}$ \\
Sodium & $133 \mathrm{mEq} / \mathrm{L}$ & $136-148 \mathrm{mEq} / \mathrm{L}$ \\
Potassium & $3.96 \mathrm{mEq} / \mathrm{L}$ & $3.6-5.0 \mathrm{mEq} / \mathrm{L}$ \\
Glucose & $215 \mathrm{mg} / \mathrm{dL}$ & $70-109 \mathrm{mg} / \mathrm{dL}$ \\
Hemoglobin A1c & $7.7 \%$ & $\leq 6.5 \%$ \\
\hline
\end{tabular}

vancomycin every $12 \mathrm{~h}$. Lumbago occurred on hospital day 2. A plain lumbar T1-weighted MRI scan showed a low signal intensity in the vertebral body endplate of the 4th and 5th lumbar vertebrae, and a short-tau inversion recovery image showed a mildly hyperintense signal in the region dipping below the posterior side of the 5 th lumbar vertebra (Fig. 1); consequently, purulent spondylitis and epidural abscess were diagnosed. The results of other tests such as the spinal fluid test, head MRI, thoracoabdominal contrast CT, and transesophageal echocardiography did not indicate infection. Pneumococcus was detected on blood culture, and the antimicrobial drugs were changed to $2 \mathrm{~g}$ ampicillin (ABPC) every $6 \mathrm{~h}$ from hospital day 3 . The blood culture result on hospital day 3 was negative. To normalize the white blood cell count, CRP level, and blood sedimentation rate and to improve $\mathrm{CT}$ findings, antimicrobial drug treatment was administered for a total of 9 weeks.

\section{Case 2}

The patient was a 60-year-old man who was the husband of the patient described above. He experienced lumbago on the same morning his wife was hospitalized. Fever and disturbance of consciousness occurred in the evening, and he visited the emergency room at another hospital. He had completed the course of neoadjuvant and adjuvant chemotherapy and radiation for glioblastoma 6 years ago, and was able to carry out his daily activities independently. He had no medical history of pneumonia or a history of pneumococcal vaccination. Although right lumbar pain was observed, the origin of fever was unknown; antimicrobial treatment was initiated with $4.5 \mathrm{~g}$ piperazine/tazobactam every $8 \mathrm{~h}$. The results of the blood test taken at hospitalization are shown in Table 2. Pneumococcus was detected in his blood culture as well, and the regimen was changed to $2 \mathrm{~g} \mathrm{ABPC}$ every $6 \mathrm{~h}$. There were abnormal findings in the lumbar MRI scan taken on hospital day 2. Nonetheless, the

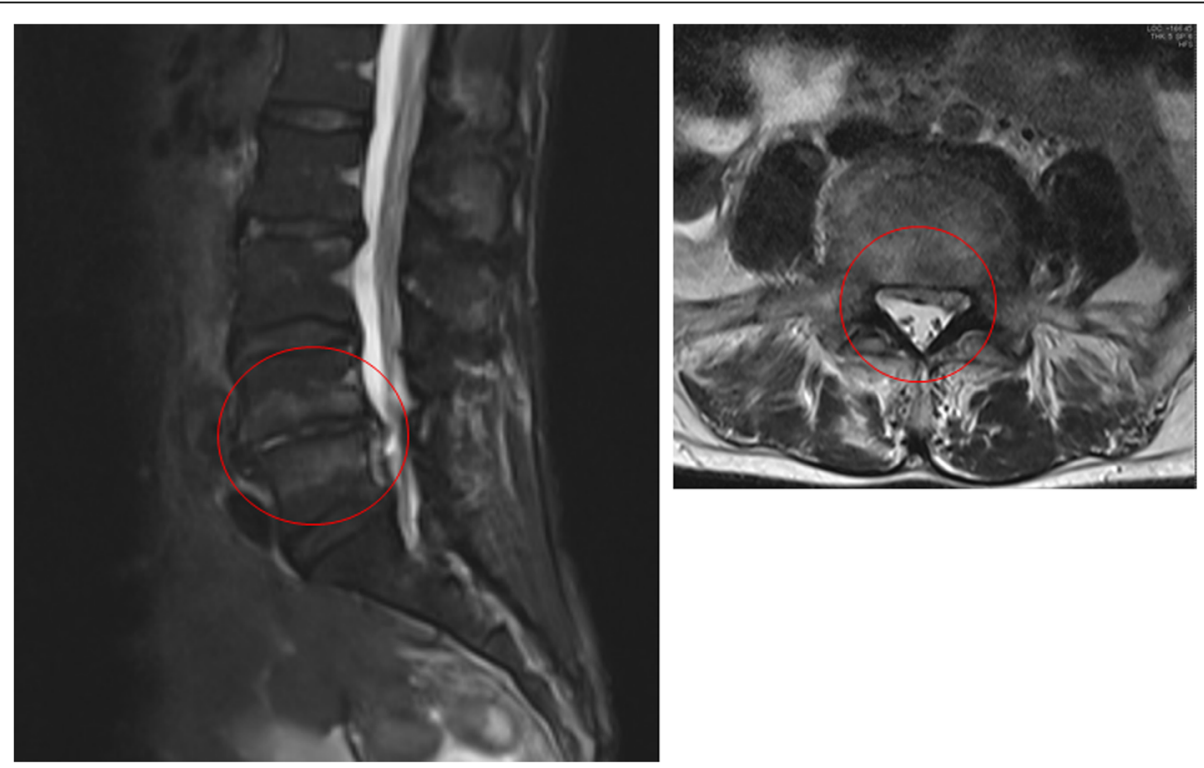

Fig. 1 Lumbar MRI-short-tau inversion recovery (STIR) image (hospital day 3). An STIR image shows mildly hyperintense signal (red circle) in the vertebral body endplate of lumbar segments 4 and 5, which dips down on the posterior side of the 5th lumbar vertebra 
Table 2 Laboratory data of Case 2 on admission

\begin{tabular}{lll}
\hline Parameter & Recorded value & Standard value \\
\hline White blood cell count & $8.75 \times 10^{9} / \mathrm{L}$ & $4.50-7.50 \times 10^{9} / \mathrm{\mu L}$ \\
$\quad$ Neutrophils & $82.4 \%$ & \\
$\quad$ Lymphocytes & $13.6 \%$ & \\
Hemoglobin & $16.4 \mathrm{~g} / \mathrm{dL}$ & $11.3-15.2 \mathrm{~g} / \mathrm{dL}$ \\
Hematocrit & $49.5 \%$ & $36-45 \%$ \\
Platelets & $81 \times 10^{9} / \mathrm{L}$ & $130-350 \times 10^{9} / \mathrm{L}$ \\
C-reactive protein & $25.0 \mathrm{mg} / \mathrm{dL}$ & $\leq 0.60 \mathrm{mg} / \mathrm{dL}$ \\
Total protein & $6.3 \mathrm{~g} / \mathrm{dL}$ & $6.9-8.4 \mathrm{~g} / \mathrm{dL}$ \\
Albumin & $3.7 \mathrm{~g} / \mathrm{dL}$ & $3.9-5.1 \mathrm{~g} / \mathrm{dL}$ \\
Aspartate aminotransferase & $182 \mathrm{U} / \mathrm{L}$ & $11-30 \mathrm{U} / \mathrm{L}$ \\
Alanine aminotransferase & $102 \mathrm{U} / \mathrm{L}$ & $4-30 \mathrm{U} / \mathrm{L}$ \\
Lactate dehydrogenase & $396 \mathrm{U} / \mathrm{L}$ & $109-216 \mathrm{U} / \mathrm{L}$ \\
Creatine phosphokinase & $360 \mathrm{U} / \mathrm{L}$ & $40-150 \mathrm{U} / \mathrm{L}$ \\
Blood nitrogen urea & $45.0 \mathrm{mg} / \mathrm{dL}$ & $8-20 \mathrm{mg} / \mathrm{dL}$ \\
Creatinine & $1.02 \mathrm{mg} / \mathrm{dL}$ & $0.63-1.03 \mathrm{mg} / \mathrm{dL}$ \\
Sodium & $142 \mathrm{mEq} / \mathrm{L}$ & $136-148 \mathrm{mEq} / \mathrm{L}$ \\
Potassium & $3.9 \mathrm{mEq} / \mathrm{L}$ & $3.6-5.0 \mathrm{mEq} / \mathrm{L}$ \\
Glucose & $122 \mathrm{mg} / \mathrm{dL}$ & $70-109 \mathrm{mg} / \mathrm{dL}$ \\
Hemoglobin A1c & $5.7 \%$ & $\leq 6.5 \%$ \\
\hline
\end{tabular}

results of the spinal fluid test, head MRI, thoracoabdominal contrast $\mathrm{CT}$, transesophageal echocardiography, did not reveal presence of infection at other sites. Because lumbago persisted, MRI was performed again on hospital day 9; the consequent MRI results revealed purulent spondylitis (Fig. 2). The patient was transferred to our hospital on hospital day 9. To normalize white blood cell count, CRP level, and blood sedimentation rate and to improve CT findings, antimicrobial drug treatment was carried out for a total of 9 weeks.

Both patients tolerated the antimicrobial treatment well, and recovered completely. A 13-valent pneumococcal conjugate vaccine was administered initially, and a 23-valent pneumococcal polysaccharide vaccine was administered 1 year later in both patients. More than 1 year has elapsed since the completion of treatment, and there has been no recurrence.

In the bacterial strain analysis (Table 3 ) performed on the samples from both patients, the capsule serotype was $12 \mathrm{~F}$ identified by the capsule quelling reaction using rabbit antisera (Statens Serum Institute, Copenhagen, Denmark). Drug sensitivity test was performed using a dry plate Eiken (Eiken Chemical Co., Tokyo, Japan), and was performed in accordance with CLSI M100-S-18 (hemosupplemented Mueller-Hinton broth, 22-h culture). The drug sensitivity in both strains was similar. As the next step, we performed a sequence typing match using the defined genetic sequence of the pneumococci was determined (aroE, gdh, gki, recP, spi, xpt, ddl) according to the method described in http://spneumo niae.mlst.net/, and it was compared with the sequence information present in the existing databases. Both strains matched completely.

\section{Discussion and conclusions}

Here, we report the case of pneumococcal bacteremia and purulent spondylitis occurring simultaneously in both a husband and wife. To the best of our knowledge, this is the first report in which pneumococcal bacteremia and purulent spondylitis have occurred simultaneously.
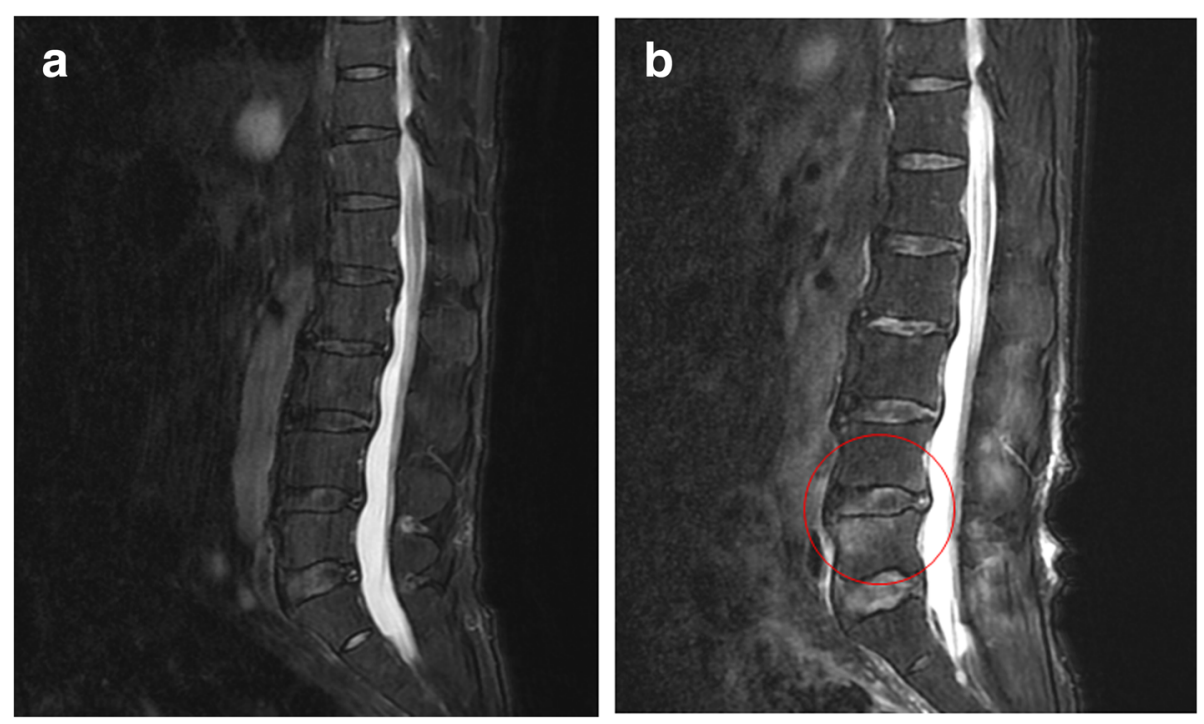

Fig. 2 Lumbar MRI-STIR image. a No abnormalities on hospital day 2 were noted (b) A mildly hyperintense signal was observed at lumbar segments 4 and 5 on hospital day 9 (red circle) 
Table 3 Results of bacterial strain analysis

\begin{tabular}{|c|c|c|c|c|c|c|c|c|c|c|c|}
\hline \multicolumn{6}{|l|}{ By serotype } & \multicolumn{6}{|l|}{ Serotype } \\
\hline \multicolumn{6}{|l|}{ Case 1} & \multicolumn{6}{|l|}{ Type $12 \mathrm{~F}$} \\
\hline \multicolumn{6}{|l|}{ Case 2} & \multicolumn{6}{|l|}{ Type 12F } \\
\hline \multicolumn{12}{|c|}{ Drug sensitivity (g/mL) } \\
\hline Strain & PCG & $\mathrm{ABPC}$ & CTX & TBPM & PAPM & MEPM & CDTR & EM & CLDM & VCM & TFLX \\
\hline Case 1 & 0.06 & $\leq 0.03$ & $\leq 0.03$ & $\leq 0.008$ & $\leq 0.008$ & 0.015 & $\leq 0.03$ & $\geq 8$ & $\geq 8$ & 0.25 & $\leq 0.12$ \\
\hline Case 2 & 0.06 & $\leq 0.03$ & 0.06 & $\leq 0.008$ & $\leq 0.008$ & 0.015 & $\leq 0.03$ & $\geq 8$ & $\geq 8$ & 0.25 & $\leq 0.12$ \\
\hline \multicolumn{12}{|c|}{ Sequence typing } \\
\hline Strain & & ST & $\operatorname{aroE}$ & Gdh & Gki & & rec $P$ & spi & $x p t$ & $d d l$ & \\
\hline Case 1 & & 4846 & 12 & 32 & 111 & & 1 & 13 & 48 & 6 & \\
\hline Case 2 & & 4846 & 12 & 32 & 111 & & 1 & 13 & 48 & 6 & \\
\hline
\end{tabular}

These cases revealed the following findings: 1) pneumococcal bacteremia and purulent spondylitis occurred in both patients; 2) when purulent spondylitis is suspected, imaging tests, if initially negative, should be repeated.

Pneumococcal infection is known to be transmitted in the carrier state among adults in community and family settings, where they are in close proximity with one another $[2,3]$. Moreover, the transmission of pneumococcal pneumonia has been reported to occur within families $[4,5]^{\cdot}$ In the present case, it was assumed that the infant living with the patients (i.e., the patients' grandchild) was a carrier, and contact between them resulted in simultaneous infection; however, bacteriological tests were not performed for the infant for ethical and health insurance purposes.

In Japan, $14.2 \%$ of the pneumococci isolated from invasive pneumococcal infection between August 2006 and July 2007 were reported to be of serotype 12F [6]. In the present case, the capsule serotype of the airborne-transmitted pneumococci was of the highly invasive type $12 \mathrm{~F}$, which is considered to have led to the purulent spondylitis with bacteremia. Since the serotype of the pneumococcal strain that had led to the rare complication of spondylitis, was the same in both patients, we decided to explore virulence factors other than the serotype, which confirmed these bacteria were identical.

It has been reported that the imaging findings of purulent spondylitis might be delayed [7, 8]. Hence, if physical findings are repeatedly evaluated and purulent spondylitis is suspected from localized pain or other symptoms that gradually appear at the vertebral site, MRI must be reperformed [7]. Persistent lumbago was observed in the present cases as well, and performing tests repeatedly when purulent spondylitis was suspected proved to be useful for diagnosis.

The Infectious Diseases Society of America (IDSA) guidelines [9] indicate a minimum of 6-week treatment for purulent spondylitis, since in cases where non-oral drug therapy is administered for less than 4 weeks, the relapse rate is reported to increase to $25 \%$ [10]. However, the period of antimicrobial drug administration for treating general infections is 14 days or less, and thus, early diagnosis is required; an appropriate treatment period will thereby contribute to a lower frequency of relapse.

In conclusion, a case of simultaneous occurrence of pneumococcal bacteremia and purulent spondylitis in a woman and her husband is described. Transmission of pneumococcal infection can occur between close family members; hence, when a close family member of an individual with confirmed pneumococcal infection presents with fever, the possibility of transmission of pneumococcal infection must be considered.

\section{Abbreviations \\ ABPC: Ampicillin; CLSI: Clinical and Laboratory Standards Institute; CRP: C- reactive protein; $C T$ : Computed tomography; IDSA: Infectious Diseases Society of America; MRI: Magnetic resonance imaging}

\section{Acknowledgments}

None.

Funding

Not applicable.

Availability of data and materials

All data supporting our findings are contained within this published article.

Authors' contributions

KG managed the case and prepared and revised the manuscript. TK assisted with manuscript preparation, correction, and revision of the manuscript. BC assisted with data analysis and revision of the manuscript. HA assisted with manuscript revision and prepared the artwork. All authors have read and approved the final version of the manuscript.

Ethics approval and consent to participate

Ethics approval and consent for this case report were waived.

Consent for publication

Written informed consent was obtained from both patients for the publication of this case report and accompanying images. A copy of the written consent is available for review by the Editor of this journal.

Competing interests

The authors declare that they have no competing interests. 


\section{Publisher's Note}

Springer Nature remains neutral with regard to jurisdictional claims in published maps and institutional affiliations.

\section{Author details}

'Department of Internal Medicine, Hyogo Prefectural Kaibara Hospital, 5208-1, Kaibara, Kaibara-cho, Tanba, Hyogo 669-3395, Japan. ${ }^{2}$ Division of Community Medicine and Career Development, Kobe University Graduate School of Medicine, 2-1-5, Arata-cho, Hyogo-ku, Kobe, Hyogo 652-0032, Japan. ${ }^{3}$ Department of Bacteriology I, National Institute of Infectious Diseases, Tokyo, Japan.

Received: 27 May 2018 Accepted: 4 December 2018

Published online: 17 December 2018

\section{References}

1. Nuorti JP, Butler JC, Crutcher JM, Guevara R, Welch D, Holder P, et al. An outbreak of multidrug-resistant pneumococcal pneumonia and bacteremia among unvaccinated nursing home residents. N Engl J Med. 1998;338:1861-8.

2. Regev-Yochay G, Raz M, Dagan R, Porat N, Shainberg B, Pinco E, et al. Nasopharyngeal carriage of Streptococcus pneumoniae by adults and children in community and family settings. Clin Infect Dis. 2004;38:632-9.

3. Goldblatt D, Hussain M, Andrews N, Ashton L, Virta C, Melegaro A, et al. Antibody responses to nasopharyngeal carriage of Streptococcus pneumoniae in adults: a longitudinal household study. J Infect Dis. 2005;192:387-93.

4. Kellner JD, Gibb AP, Zhang J, Rabin HR. Household transmission of Streptococcus pneumoniae, Alberta, Canada. Emerg Infect Dis. 1999;5:154-8.

5. Ujiie M, Izumi S, Takeshit N, Takasaki J, Mizuno Y, Kato Y, et al. Household transmission of pneumococcal pneumonia associated with pandemic influenza (H1N1) 2009. Nihon Kokyuki Gakkai Zasshi. 2010;48:322-7 [Article in Japanese].

6. Chiba N, Morozumi M, Sunaoshi K, Takahashi S, Takano M, Komori T, et al. Serotype and antibiotic resistance of isolates from patients with invasive pneumococcal disease in Japan. Epidemiol Infect. 2010;138:61-8.

7. Ozaka A, Onishi T, Ueda U, Kenzaka T, Matsumura M. A case of pyogenic vertebral osteomyelitis: importance of physical examination for correct diagnosis. J Gen Fam Med. 2016:17:160-3.

8. Ledermann HP, Schweitzer ME, Morrison WB, Carrino JA. MR imaging findings in spinal infections: rules or myths? Radiology. 2003;228:506-14.

9. Berbari EF, Kanj SS, Kowalski TJ, Darouiche RO, Widmer AF, Schmitt SK, et al. 2015 Infectious Diseases Society of America (IDSA) clinical practice guidelines for the diagnosis and treatment of native vertebral osteomyelitis in adults. Clin Infect Dis. 2015;61:e26-46.

10. Gasbarrini AL, Bertoldi E, Mazzetti M, Fini L, Terzi S, Gonella F, et al. Clinical features, diagnostic and therapeutic approaches to haematogenous vertebral osteomyelitis. Eur Rev Med Pharmacol Sci. 2005;9:53-66.

Ready to submit your research? Choose BMC and benefit from:

- fast, convenient online submission

- thorough peer review by experienced researchers in your field

- rapid publication on acceptance

- support for research data, including large and complex data types

- gold Open Access which fosters wider collaboration and increased citations

- maximum visibility for your research: over $100 \mathrm{M}$ website views per year

At $\mathrm{BMC}$, research is always in progress.

Learn more biomedcentral.com/submissions 